\title{
POSTOPERATIVE VOMITING IN PATIENTS AFTER LAPAROSCOPIC SURGERY
}

\author{
Ivanov K., V. Ignatov, N. Kolev, A. Tonev \\ Department of General and Operative Surgery, St. Marina Varna University Hospital
}

Reviewed by: assoc. prof. R. Radev

\begin{abstract}
BACKGROUND: Postoperative nausea and vomiting (PONV) is common after anaesthesia and surgery. We decided to evaluate metoclopramide, dexamethasone, and their combination in preventing PONV in patients undergoing laparoscopic surgery. METHOD: 396 patients were studied. Four groups were created: group 1 received metoclopramide postoperatively; group 2 received dexamethasone following anaesthesia; and group 3 received dexamethasone following anaesthesia and metoclopramide before end of anaesthesia. Results were compared to group without anti-emetic. PONV incidence, basal and active mean visual analogue pain scores, time to first analgesia request, side effects, and well-being score were recorded at first $24 \mathrm{~h}$ postoperatively. RESULTS: Literature total incidence of PONV was $60 \%$ in control group devoid of anti-emetic but $45 \%$ of PONV was seen in Group 1 with metoclopramide, Group 2 -23\% with dexamethasone, and Group 3-12\% with the combination of dexamethasone and metoclopramide. Anti-emetic rescue was not required in dexamethasone plus metoclopramide group or group with only dexamethasone, compared with four patients in the metoclopramide group and six patients in the control group. CONCLUSION: Dexamethasone or dexamethasone + metoclopramide combination was more effective in preventing PONV than metoclopramide or lack of anti-emetic.
\end{abstract}

Key words: postoperative nausea, vomiting, laparoscopic surgery

\section{INTRODUCTION}

Postoperative nausea and vomiting (PONV) is one of the most common complaints following anaesthesia and surgery (1) Despite improvements in anaesthesia, $20-30 \%$ of patients still experience nausea and vomiting after surgery $(2,3,4,5)$. A large clinical trial of postoperative nausea and vomiting showed that $4 \mathrm{mg}$ ondansetron, $4 \mathrm{mg}$ dexamethasone, or 1.25 $\mathrm{mg}$ droperidol were effective, and that combinations of these drugs had an additive effect (2). Dexamethasone was recommended as the first line drug, as it is safe and cheap. Data on metoclopramide as an anti-emetic after surgery are contradictory. A meta-analysis found that an intravenous dose of $10 \mathrm{mg}$ had only a marginal effect, (6) but because of its complex mode of action (it binds to dopamine, serotonin, and histamine receptors), metoclopramide remains an interesting drug for preventing postoperative nausea and vomiting (7). Studies have concluded that metoclopramide is ineffective in this context, but the timing of administration and use of larger doses were not investigated fully $(8,9,10,11)$. We investigated the ef-

Address for correspondence:

K. Ivanov, Dept. of General and Operative Surgery, St. Marina University Hospital, Prof. P. Stoyanov Medical University of Varna; BG-9002 Varna, 1, Hristo Smirnenski Street, Bulgaria e-mail: teraton@abv.bg ficacy of metoclopramide, dexamethasone, and their combination in preventing PONV in patients undergoing laparoscopic surgery.

\section{MATERIAL AND METHODS}

We screened 460 patients hospitalised in the clinic of intensive care and clinic of general and operative surgery in St. Marina University hospital Varna, Bulgaria, from 2001 to 2006 operated laparoscopically. We included 396 in the study and analysed all of them (Table 1) and summarises demographic data and putative risk factors. A data for non-treated patients with anti-emetic therapy was observed by an Internet literature survey using the following keywords: post operative nausea and vomiting (PONV) $(12,13)$. These results formed a group of patients assigned as control group. The median incidence of PONV reported in the observed literature was $62 \%$. They were surgically treated and no anti-emetic therapy was administered. Our Group 1 from the 346 patients was surgically treated in our Clinic and given anti-emetic therapy of $2 \times 10 \mathrm{mg}$ of metoclopramide. This group was retrospectively observed. Group 2, comprising 25 patients prospectively observed, was treated intraoperatively with dexamethasone $8 \mathrm{mg}$. A Group 3 25 patients prospectively observed was treated with a combination of dexamethasone $8 \mathrm{mg}$ after the induction of anaesthesia 
and metoclopramide $10 \mathrm{mg}$ before the end of anaesthesia. We considered patients for inclusion if they were aged 18 years or more and having balanced anaesthesia during laparoscopic fundoplicatons, laparoscopic cholecystectomy, laparoscopic colorectal surgery, laparoscopic hernioplasty, laparascopic varicocele treatment, laparoscopic gynaecologic surgery, laparoscopic abdominal exploration and biopsy, and laparoscopic appendectomy.

\section{PROTOCOL}

Exclusion criteria were contraindications for metoclopramide and dexamethasone; use of antiemetic or antidepressive drugs; patient classified as ASA grade IV (has severe systemic disease that is a constant threat to life); presence of extra pyramidal motoric disease, malignant hyperthermia, hepatic insufficiency, pheochromocytoma, mechanical ileus or epilepsy; intended or probable postoperative administration of protocol, artificial respiration, or stomach tube; patient pregnant or breast feeding. Obey of clinical protocol is pursue with colleagues from Clinic of anaesthesia and intensive care from our hospital.

\section{DOCUMENTATION AND FOLLOW-UP}

We recorded eligibility criteria and history on the day before surgery. During surgery, details of anaesthesia, relevant drug, and adverse reactions were recorded. Twenty four hours after the end of surgery the anaesthesiologists and surgeon visited the patients to record any nausea and vomiting, other adverse events, and relevant drugs.

\section{RESULTS}

thesia and metoclopramide $10 \mathrm{mg}$ before the end of anaesthesia report complains in $12 \%$ of the cases.

\section{Adverse events}

Only intraoperatively hypotension and tachycardia were clearly related to the applied anti emetic therapy and these events correlated with each other.

\section{Predictors of nausea and vomiting and adverse reactions}

Known predictors of postoperative nausea and vomiting- female sex, history of nausea and vomiting after surgery or motion sickness, non-smoking, and postoperative opioids - were associated with increased rates of postoperative nausea and vomiting. Late application of opioids increased postoperative nausea and vomiting much more than early application. The frequency of nausea and vomiting and adverse reactions depended on the type of surgery. The pattern of this association was different for early and late events. Like smoking, alcohol consumption was associated with less frequent postoperative nausea and vomiting. Whereas the number of cigarettes smoked each day had no effect, we detected a significant difference between moderate and higher alcohol consumption. Early postoperative nausea and vomiting was less frequent in patients aged 50 or more but late episodes were more frequent, as were adverse reactions. Obesity was not associated with nausea and vomiting, but it seemed to protect against adverse reactions. Late postoperative nausea and vomiting was more likely to occur in patients who had had nausea and vomiting in the early phase. Rescue drugs given for early postoperative nausea and vomiting prevented new events in the later time period.

Table 1. Postoperative nausea and vomiting outcome (\%); Values are number (\%)

\begin{tabular}{||l|c|c|c||}
\hline \hline Variable & Group 1 (n-346) & Group 2 (n-25) & Group 3 (n-25) \\
\hline All types of PONV & $156(45)$ & $6(23)$ & $3(12)$ \\
\hline Nausea (regardless vomiting) & $91(26)$ & $3(12)$ & $2(8)$ \\
\hline Vomiting (regardless vomiting) & $97(28)$ & $5(20)$ & $2(8)$ \\
\hline Early form (0-12 hours after surgery) & $95(27)$ & $3(12)$ & $2(8)$ \\
\hline Late form(>12-24 hours after surgery) & $61(18)$ & $3(12)$ & $1(4)$ \\
\hline Multiple episodes of PONV & $55(16)$ & $3(12)$ & $1(4)$ \\
\hline
\end{tabular}

\section{End points}

The addition of $2 \times 10 \mathrm{mg}$, metoclopramide, postoperatively reduced the cumulative incidence of postoperative nausea and vomiting from $62 \%$ in controlled group to the $42 \%$ in comparison with Group 1. The application of $8 \mathrm{mg}$ dexamethasone in the Group 2 intraoperatively reduced the cumulative incidence of postoperative nausea and vomiting to $24 \%$. The patients in Group 3 who received a combination of dexamethasone $8 \mathrm{mg}$ after the induction of anaes-

\section{DISCUSSION}

No single drug has proved to be a universal solution to postoperative nausea and vomiting. It is not feasible to give very high doses of such drugs because of saturation effects and safety, so combinations of antiemetic and corticosteroid drugs are a possibility. We found that $8 \mathrm{mg}$ dexamethasone added to the basic intervention of $10 \mathrm{mg}$ metoclopramide is effective, safe, and cheap. 


\section{Strengths and limitations}

Our study design allowed us to investigate the effects of separate application and the combined application of drugs from two pharmacologic groups. In retrospect, we should have recorded more details on hypotension and tachycardia. Although these adverse events were short lasting and self limiting in most cases, some facts beyond the clinical impression might have been useful (such as the need for treatment).

\section{COMPARISON WITH OTHER STUDIES}

A meta-analysis reported that $10 \mathrm{mg}$ metoclopramide was clinically ineffective and did not improve when combined with $8 \mathrm{mg}$ dexamethason (6). Larger dosages, however, were as effective as ondansetron or droperidol when added to dexamethasone (2). A randomised double blind trial with 240 children and adults per treatment arm found that $50 \mathrm{mg}$ metoclopramide was not effective for postoperative vomiting but significantly reduced postoperative nausea and vomiting (14). Unfortunately, this paper did not say when the drug was given, and the trial was powered only for large effects. Other studies also found that $20 \mathrm{mg}$ metoclopramide was ineffective, possibly because of the small sample sizes $(40,129$, and 51 patients per group) $(15,16,17)$. Furthermore, the timing of antiemetic prophylaxis seems to influence efficacy $(18,19)$. In most of the studies, metoclopramide was given immediately after induction of anaesthesia, irrespective of its time of maximum effect and short half life. Despite the neuroleptic properties of metoclopramide, its addition to dexamethasone did not increase rates of headache, dizziness, sedation, or dry mouth. The incidences seen in our trial are similar to those of low dose droperidol (3).

\section{Clinical implications and future research}

We recommend a combination of $8 \mathrm{mg}$ dexamethasone and $10 \mathrm{mg}$ metoclopramide, given before the end of surgery. Additional drugs can then be given after surgery, but the patient's risk profile should be taken into account. Rescue drugs should be given after postoperative nausea and vomiting to prevent repeat episodes. To improve existing risk scores used in guidelines, the role of different types of surgery and of alcohol consumption should be investigated further (20).

\section{REFERENCES}

1. Nesek-Adam V, Grizelj-Stojcic E, Rasic Z, Cala Z, Mrsic V, Smiljanic A. Comparison of dexamethasone, metoclopramide, and their combination in the prevention of postoperative nausea and vomiting after laparoscopic cholecystectomy. Surg Endosc. $2007 \mathrm{Feb} 7$; [Epub ahead of print]

2. Apfel CC, Korttila K, Abdalla M, Kerger H, Turan A, Vedder I, et al. A factorial trial of six interventions for the prevention of postoperative nausea and vomiting. N Engl J Med 2004; 350:2441-51.

3. Fortney JT, Gan TJ, Graczyk S, Wetchler B, Melson T, Khalil S, et al. A comparison of the efficacy, safety, and patient satisfaction of ondansetron versus droperidol as antiemetics for elective outpatient surgical procedures. Anesth Analg 1998; 86:731-8.

4. Koivuranta $\mathrm{M}$, Laara $\mathrm{E}$, Snåre L, Alahuhta S. A survey of postoperative nausea and vomiting. $A n-$ aesthesia 1997; 52:443-9.

5. Wang JJ, Ho ST, Lee SC, Liu YC, Liu YH, Liao YC. The prophylactic effect of dexamethasone on postoperative nausea and vomiting in women undergoing thyroidectomy: a comparison of droperidol with saline. Anesth Analg 1999; 89:200-3.

6. Henzi I, Walder B, Tramer MR.

Metoclopramide in the prevention of postoperative nausea and vomiting: a quantitative systematic review of randomized, placebocontrolled studies. $\mathrm{Br} J$ Anaesth 1999; 83:761-71.

7. Olthoff D. Antiemetika. In: Olthoff D, ed. Arzneimittelanwendungen in der Anästhesie. Stuttgart: Wissenschaftliche Verlagsgesellschaft, 2003:511-34.

8. Fujii Y, Tanaka H, Toyooka H. The effects of dexamethasone on antiemetics in female patients undergoing gynecologic surgery. Anesth Analg 1997; 85:913-7.

9. Maddali MM, Mathew J, Fahr J, Zarroug AW. Postoperative nausea and vomiting in diagnostic gynaecological laparoscopic procedures: comparison of the efficacy of the combination of dexamethasone and metoclopramide with that of dexamethasone and ondansetron. J Postgrad Med 2003; 49:302-6.

10. Tzeng JI, Hsing $\mathrm{CH}$, Chu $\mathrm{CC}$, Chen $\mathrm{YH}$, Wang JJ. Low-dose dexamethasone reduces nausea and vomiting after epidural morphine: a comparison of metoclopramide with saline. J Clin Anesth 2002; 14:19-23.

11. Nesek-Adam V, Grizelj-Stojcic E, Mrsic V, Smiljanic A, Rasic Z, Cala Z. Prophylactic antiemetics for laparoscopic cholecystectomy: droperidol, metoclopramide, and droperidol plus metoclopramide. J Laparoendosc Adv Surg Tech A. 2004 Aug;14(4):212-8.

12. Chen MS, Hong CL, Chung HS, Tan PP, Tsai $\mathrm{CC}, \mathrm{Su} \mathrm{HH}$, Wong $\mathrm{CH}$. Dexamethasone effectively reduces postoperative nausea and vomiting in a general surgical adult patient population. Chang Gung Med J. 2006 Mar-Apr; 29 (2):175-81.

13. Habib AS, Chen YT, Taguchi A, Hu XH, Gan TJ. Postoperative nausea and vomiting following inpatient surgeries in a teaching hospital: a retrospective database analysis. Curr Med Res Opin. 2006 Jun; 22 (6):1093-9.

14. Apfel CC, Kranke P, Katz MH, Goepfert C, Papenfuss T, Rauch S, et al. Volatile anaesthetics may be the main cause of early but not delayed vomiting: a randomized controlled trial of factorial design. Br J Anaesth 2002; 88:659-68.

15. Eberhart LHJ, Seeling W, Ulrich B, Morin AM, Georgieff M. Dimenhydrinate and 
metoclopramide alone or in combination for prophylaxis of PONV. Can J Anesth 2000; 47:780-5.

16. Piper SN, Suttner SW, Röhm KD, Maleck WH, Larbig E, Boldt J. Dolasetron, but not metoclopramide prevents nausea and vomiting in patients undergoing laparoscopic cholecystectomy. Can $J$ Anesth 2002; 49:1021-8.

17. Quaynor H, Raeder JC. Incidence and severity of postoperative nausea and vomiting are similar after metoclopramide $20 \mathrm{mg}$ and ondansetron $8 \mathrm{mg}$ given by the end of laparoscopic cholecystectomies. Acta Anaesthesiol Scand 2002; 46:109-13.

18. Korttila KT, Jokinen JD. Timing of administration of dolasetron affects dose necessary to prevent postoperative nausea and vomiting. $J$ Clin Anesth 2004; 16:364-70.

19. Wang JJ, Ho ST, Tzeng JI, Tang CS. The effect of timing of dexamethasone administration on its efficacy as a prophylactic antiemetic for postoperative nausea and vomiting. Anesth Analg 2000; 91:136-9.

20. Gan TJ, Meyer T, Apfel CC, Chung F, Davis $\mathrm{PJ}$, Eubanks S, et al. Consensus guidelines for managing postoperative nausea and vomiting. Anesth Analg 2003; 97:62-71. (Accepted 31 May 2006)

21. Flather MD, Farkouh ME, Pogue JM, Yusuf S. Strengths and limitations of meta-analysis: larger studies may be more reliable. Control Clin Trials 1997; 18:568-79.

22. Eberhart LHJ, Morin AM, Felbinger TW, Falkner Y, Georgieff M, Seeling W. Results of a survey concerning postoperative nausea and vomiting [in German]. Anasthesiol Intensivmed Notfallmed Schmerzther 1998; 33:545-51.

23. Schuneck R, Speck-Hergenruder J, Eberhart LHJ. Anaesthetic procedures and use of antiemetics in ambulatory anaesthesia [in German]. Anaesthes Intensivmed 2002; 43:695-9. 